\title{
THE RELATIONSHIP BETWEEN SYSTEMIC STEROID THERAPY AND THE LEVEL OF SERUM IGE IN ALLERGIC FUNGAL RHINOSINUSITIS
}

\author{
Nabil Galal Zeid, Ahmed Shawky Mohammed, Mahmoud El-Sayyed El-Fouly and Mahmoud Sherif El- \\ Essawy \\ Department of Otorhinolaryngology, Faculty of medicine, Cairo University, Cairo, Egypt
}

Corresponding

Author: Dr. Mahmoud

Sherif El-Essawy

Egypt.E-mail:m-

essawy@hotmail.com.

Tel.

No:00201016581112
Background: Adequate study of allergic fungal rhinosinusitis (AFRS) helped better understanding of the nature of the disease. It involves immediate hypersensitivity to fungus present in the nose and sinuses. This involves immunoglobulin E. Therefore the presence of serum $\mathrm{IgE}$ indicates the presence of the allergic reaction. The objective is to evaluate the relationship between systemic steroid therapy and the level of serum IgE in allergic fungal rhinosinusitis indicating adequate therapy. This is a prospective study.

Subjects and Methods: Forty patients diagnosed as allergic fungal sinusitis were randomly divided into two equal groups: group A was given postoperative systemic steroids and local steroids, while group B was not given systemic steroids (local steroids only). The patients were followed up for three and six months by testing IgE levels in blood.

Results: The total number of patients who had more than $10 \%$ increase in serum IgE after 6 months post-operative was 18 patients. Six of them were from group A (Systemic steroids) and 12 were from group B (Local steroids).

Conclusion: There was a strong relation between systemic steroid therapy and the level of serum IgE. Thus, AFS should be treated by systemic steroids for a prolonged period after adequate clearance of the sinuses. Patients should be followed up at close intervals post-operative using serum Ig $\mathrm{E}$ as it can indicate increased fungal load and the need for further treatment.

Key words: Allergic, Fungal, Sinusitis, Ig E, Steroids.

\section{INTRODUCTION}

C haracteristics rhinosinusitis

of allergic

fungal alerger allergic mucin that entangles the fungus and obstructs the sinus openings. The fungal process involved in allergic fungal sinusitis is not tissue invasive, which means an allergic, non-infectious, disease ${ }^{[1]}$. The commonest offending fungi are Dematiaceous fungi, with Bipolaris spicifera mostly encountered ${ }^{[2]}$.

The immunologic basis (pathogenesis) of AFRS involves an immediate hypersensitivity ( $\mathrm{IgE}$ ) reaction specific to the fungus, together with other antibodies. Serological studies of AFS are very similar to allergic bronchopulmonary aspergillosis (ABPA) and include fungus-specific IgG (sIgG) and fungus-specific $\operatorname{IgE}(\mathrm{s} \operatorname{IgE})^{[3]}$.

Type I hypersensitivity reactions are mediated by IgE. The physiology of type I hypersensitivity reactions involves the change from normal $\mathrm{IgM} / \mathrm{IgG}$ antibody reaction to an IgE mediated reaction against a certain allergen during sensitization. The development of type I hypersensitivity consists of three phases: (1) the allergy-induction phase; (2) the allergystimulation phase; and (3) the effector phase ${ }^{[4]}$.

Available choices for the effective management of AFRS were not previously studied thoroughly. Surgery alone is not enough for the management of AFRS due to high postoperative recurrence rates. Systemic antifungal medications have shown poor influence on needing re-surgery. Several authors contraindicate these drugs, which is logic since the fungus is extramucosal and the disease is not a fungal infection ${ }^{[5]}$.

The true and full role of fungus-specific antibodies in fungal infections was not explored until twenty years ago. But later on, various researches have shown that specific antibodies 
(fungus-specific $\operatorname{IgG}(\mathrm{sIgG})$ and fungus-specific $\operatorname{IgE}(\mathrm{sIgE}))$ could alter the prognosis of fungal diseases. Hybridoma technology was the key that enabled the linking of antibodies to various fungi, paving the path towards improved antibody efficacy ${ }^{[6]}$.

A decrease in total serum IgE after oral corticosteroid therapy was predictive of resolving disease. Therefore, postoperative follow up led to better overall outcomes for AFRS and measuring total serum IgE was effective as a follow-up tool ${ }^{[7]}$.

In this study our aim is to evaluate the relationship between the level of total serum IgE and the administration of systemic steroids in patients with Allergic Fungal Sinusitis as an indicator of adequate therapy.

\section{SUBJECTS AND METHODS}

This is a Prospective Study (Randomized control study) that was performed at the otorhinolaryngology department, Kasr ElAini Hospital, Cairo University during the period from July 2013 to January 2015. This study has been approved by the ethical committee. It included 40 patients who were diagnosed at the outpatient clinic as Allergic Fungal RhinoSinusitis.

These patients were diagnosed as Allergic fungal rhinosinusitis according to the major and minor criteria. Two major with two minor criteria were sufficient for diagnosis ${ }^{[8]}$.

\section{The major criteriae included:}

1) Presence of nasal polyps with allergic mucin,

2) IgE mediated hypersensitivity,

3) Characteristic computerised tomographic scan features,
4) Eosinophilic nasal mucosa

5) Non-invasive fungal colonies on smear, culture or histopathology.

The minor criteriae included:

1) History of bronchial asthma,

2) Unilateral predominance of polyps,

3) Eosinophilia in peripheral smear,

4) Charcot- leyden crystals on histopathology,

5) Radiographic bone erosion.

All patients with allergic fungal rhinosinusitis were included in this study. All geographic and demographic distributions are included. All patients were within the age group of 20-50 years except for 7 patients ( 5 teenagers and 2 above 50 years). Only patients with immune-compromized state and patients who were found to have tissue invasion were excluded, as these fall into a different category of fungal sinusitis.

The 40 patients who shared in this study were randomly divided into 2 groups (20 patients in each group). Patients in the first group (Group A) received both systemic and local steroid therapy post-operatively while patients in the other group (Group B) were only given local steroids as post-operative therapy.

All patients were subjected to clinical assessment including a thorough physical examination, naso-endoscopy, routine preoperative laboratory investigations, preoperative anaesethsitic consultation as well as full history taking from patient. All patients were counseled about the plan of management and procedure and signed a written consent of approval.

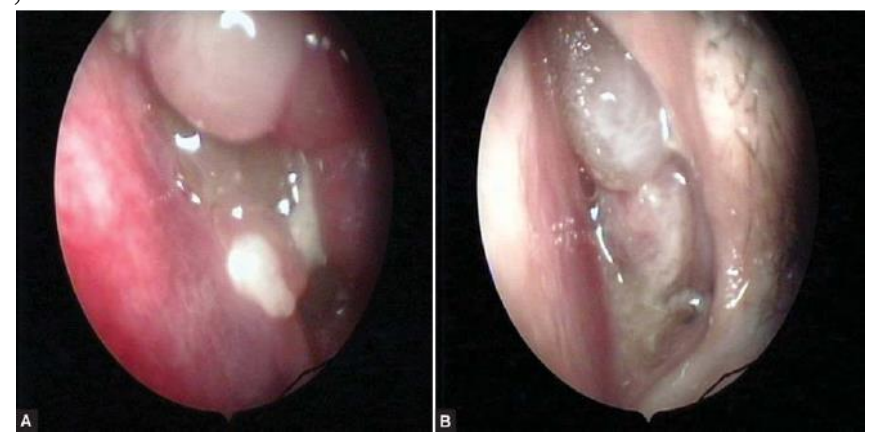

Endoscopic picture of AFRS patients showing polyps and allergic mucin. 
Level of $\operatorname{IgE}$ was evaluated in serum. Management of the patients was done accordingly. All patients needed surgical intervention ranging from middle meatal antrostomy to ethmoidectomy and sphenoidotmy. All procedures were done by the same surgeon. All procedures were done endoscopically (ESS) under general anaesthesia.

Patients stayed at the department for 2 days post-operative, non-narcotic pain killers were administered in the post-operative period. The nasal packs were removed and the patients were discharged on medical treatment according to the grouping.

Patients in group (A) who were given oral steroids were given prednisolone orally $(80$ $\mathrm{mg}$ per day for 2 weeks), tapering it over 2 more weeks. All patients were given ranitidine $150 \mathrm{mg}$ orally once per day and fluticasone nasal spray (50 micrograms) in the form of two puffs once per day. Patients in group (B) received fluticasone nasal spray only at the same dose as group (A).

The levels of serum $\operatorname{IgE}$ were evaluated at the start of the study, at 3 months and 6 months post-operative to see the relation between systemic steroid therapy and the level of IgE.

All the data was collected and statistical analysis was done on an intention to treat (ITT) basis. Analysis was done using ANOVA and the significance testing was done using the two-tailed testing. Comparing the two groups was done regarding levels of total serum $\operatorname{IgE}$ and the percentage increase in serum $\operatorname{IgE}$.

\section{RESULTS}

Forty patients of those diagnosed as AFRS accepted our plan of management and were recruited in our study. They were randomly (computerized) divided into 2 groups, without being influenced by severity, recurrence, etc. Group A (20 patients) received local and systemic steroids while group B (20 patients) received local steroid therapy only. Out of the 40 patients 25 were females and 15 were males. All patients were within the age group of 20-50 years except for 7 patients (5 teenagers and 2 above 50 years old).

The mere values of the serum $\operatorname{IgE}$ varied from one patient to another and from one laboratory to another. To overcome this and to standardize the results: the increase in the level of serum IgE from 3 months to 6 months postoperative was calculated and the percentage increase from the first value obtained postoperative (at 3 months) was obtained.

All patients had a decrease in serum IgE after 3 months of the operation. This can be explained by the decrease in the fungal load in the sinuses which means a decrease in the allergic reaction. With the progress of the disease serum IgE increases.

On obtaining the percentage increase in serum $\operatorname{IgE}$, it was found that the total number of patients who had more than $10 \%$ increase in serum IgE after 6 months post-operative was 18 patients. 6 of them were from group A (Systemic steroids) and 12 were from group B (Local steroids only). The total number of patients who had less than $10 \%$ increase in serum IgE after 6 months post-operative was 8 patients. 3 of them were from group A (Systemic steroids) and 5 were from group B (Local steroids only). The total number of patients who had a decrease in serum IgE after 6 months post-operative was 14 patients. 11 of them were from group A (Systemic steroids) and 3 were from group B (Local steroids). The results obtained were statistically analysed as follows: 


\section{DESCRIPTIVE OUTPUT}

\begin{tabular}{|c|c|c|}
\hline Patient & Group & $\%$ increase in IgE \\
\hline 1 & A & $10 \%$ \\
\hline 2 & $\mathrm{~A}$ & $-13 \%$ \\
\hline 3 & $\mathrm{~A}$ & $-10 \%$ \\
\hline 4 & $\mathrm{~A}$ & $-90 \%$ \\
\hline 5 & A & $-135 \%$ \\
\hline 6 & A & $-8 \%$ \\
\hline 7 & A & $6 \%$ \\
\hline 8 & $\mathrm{~A}$ & $-13 \%$ \\
\hline 9 & $\mathrm{~A}$ & $-27 \%$ \\
\hline 10 & $\mathrm{~A}$ & $-12 \%$ \\
\hline 11 & $\mathrm{~A}$ & $-4 \%$ \\
\hline 12 & $\mathrm{~A}$ & $2 \%$ \\
\hline 13 & $\mathrm{~A}$ & $-6 \%$ \\
\hline 14 & $\mathrm{~A}$ & $-8 \%$ \\
\hline 15 & $\mathrm{~A}$ & $16 \%$ \\
\hline 16 & $\mathrm{~A}$ & $26 \%$ \\
\hline 17 & $\mathrm{~A}$ & $14 \%$ \\
\hline 18 & $\mathrm{~A}$ & $24 \%$ \\
\hline 19 & $\mathrm{~A}$ & $28 \%$ \\
\hline 20 & $\mathrm{~A}$ & $37 \%$ \\
\hline 21 & $\mathrm{~B}$ & $10 \%$ \\
\hline 22 & $\mathrm{~B}$ & $-13 \%$ \\
\hline 23 & $\mathrm{~B}$ & $3 \%$ \\
\hline 24 & B & $-8 \%$ \\
\hline 25 & $\mathrm{~B}$ & $2 \%$ \\
\hline 26 & $\mathrm{~B}$ & $7 \%$ \\
\hline 27 & $\mathrm{~B}$ & $15 \%$ \\
\hline 28 & $\mathrm{~B}$ & $-5 \%$ \\
\hline 29 & $\mathrm{~B}$ & $4 \%$ \\
\hline 30 & $\mathrm{~B}$ & $19 \%$ \\
\hline 31 & $\mathrm{~B}$ & $15 \%$ \\
\hline 32 & B & $16 \%$ \\
\hline 33 & B & $17 \%$ \\
\hline 34 & $\mathrm{~B}$ & $21 \%$ \\
\hline 35 & B & $14 \%$ \\
\hline 36 & $\mathrm{~B}$ & $13 \%$ \\
\hline 37 & B & $30 \%$ \\
\hline 38 & $\mathrm{~B}$ & $37 \%$ \\
\hline 39 & $\mathrm{~B}$ & $40 \%$ \\
\hline 40 & B & $70 \%$ \\
\hline
\end{tabular}


Group A: \% increase in serum IgE:

The maximum $\%$ increase was $37 \%$ while the minimum was $-135 \%$ i.e. a decrease in serum $\operatorname{IgE}$.

\begin{tabular}{l|l|l|l|l|l}
\hline & Number & Minimum & Maximum & Mean & Std. Deviation \\
\hline Increase in IgE in \% & 20 & -135 & 37 & -8.15 & 40.056 \\
\hline & & & & & \\
\hline
\end{tabular}

\section{Group B: \% increase in serum IgE:}

The maximum $\%$ increase was $70 \%$ i.e. higher increase, while the minimum was $-13 \%$ i.e. a slight decrease in serum IgE.

\begin{tabular}{llllll}
\hline & Number & Minimum & Maximum & Mean & Std. Deviation \\
\hline Increase inIgE in $\%$ & 20 & -13 & 70 & 15.35 & 18.715 \\
\hline
\end{tabular}

\section{RELATIONS OUTPUT}

From the 2 previous tables, we can reach the following:

* Relation between increase in IgE in percent and study groups:

Group A showed \% decrease in serum IgE while group B showed \% increase.

\begin{tabular}{lllll}
\hline & Group & $\mathrm{N}$ & Mean & Std. Deviation \\
\hline & $\begin{array}{l}\text { Group A receiving20 } \\
\text { Increase in IgE in \% }\end{array}$ & -8.15 & 40.056 \\
\cline { 2 - 4 } & $\begin{array}{l}\text { Systemic steroids } \\
\text { local steroids }\end{array}$ & 18.715 \\
\hline
\end{tabular}

* Significance of \% increase in serum IgE level:

The $\%$ change in serum IgE were highly significant $(<0.05)$.

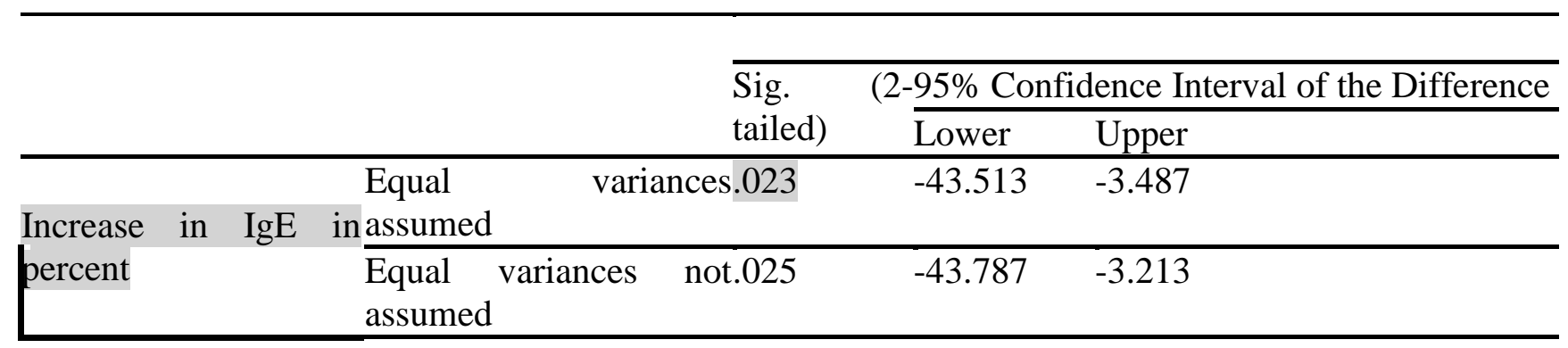

ANOVA

Increase in $\operatorname{IgE}$ in percent

\begin{tabular}{ll}
\hline & Sig. \\
\hline Between Groups & .000 \\
\hline
\end{tabular}


From the previous statistical analysis we can find that there is a significant relation between the administration of systemic steroids and the percentage increase in the serum IgE. The percentage increase in total serum $\operatorname{IgE}$ was lower in the group administering systemic steroids (sometimes there was a decrease in serum $\operatorname{IgE})$.

\section{DISCUSSION}

According to researches, AFRS is considered an allergic not an infectious disorder. Better knowledge of the mechanism of this disease resulted in great advances in its management. Medical treatment has changed greatly from an systemic antifungal medications to different local medications and immunomodulators ${ }^{[9]}$.

There is no real controversy regarding the existence of AFRS as a distinct clinicopathological entity. Diagnostic criteria are well known and accepted. The clinical, histopathological, and immunological analogy of AFRS to ABPA has been developed by a number of researchers over the past years ${ }^{[10]}$. "Allergic inflammation" is a histological term describing an inflammatory process involving variable numbers of eosinophils and lymphocytes, often with associated tissue edema. It can be confused with the term "atopy" which is also called "Type 1 immediate hypersensitivity." Atopy is often, but not always, the underlying cause of histologically defined allergic inflammation. In our study only 1 patient had associated bronchial asthma (another form of Atopy) ${ }^{[11]}$.

Diagnostic error can be reduced by reviewing the pre-operative sinus CT scan, surgical sinus histopathology and culture, operative reports, and medical work-up, including total serum $\operatorname{IgE}$ and skin testing for type I immediate hypersensitivity ${ }^{[12]}$. The previously mentioned steps are also recommended by our study as well as adherence to the diagnostic criteria that we followed in our study. The main role of $\operatorname{IgE}$ antibodies in the allergic and inflammatory reaction during the immediate and late phases is completely understood. $\mathrm{IgE}$ is the mediator of this reaction ${ }^{[13]}$.

Waxman et al ${ }^{[14]}$ suggested the intake of systemic corticosteroids immediately after an operation to clear the sinuses from the fungal load that is entangeled within the inspissated allergic mucin. This also improves mucous clearance and sinus drainage while corticosteroids reduce inflammatory reaction and polyp formation ${ }^{[15]}$. They gave this management to seven patients who responded well and improved. Our results also showed good response in patients of group A. Out of 20 patients, only 6 patients had more than $10 \%$ increase in serum $\operatorname{IgE}, 3$ had less than $10 \%$ increase and 11 had a decrease in serum $\operatorname{IgE}$ [16].

In our series all the 40 patients were essentially treated surgically. Only endoscopic approaches were used, ranging from Middle Meatal Antrostomy (MMA) to ethmoidectomies and sphenoidotomy according to the affected sinuses. Also the surgeon decided the operations according to what he prefers. All the procedures were done under general anaesthesia and patients were followed up every 3 months with serum IgE.

Kupferberg et al [17] gave oral prednisolone (40 mg per day for 4 days, $30 \mathrm{mg}$ per day for 4 days and $20 \mathrm{mg}$ per day for 1 month). This was continued at a minimal dose that kept the patient free. With this management plan, 26 adult patients with AFRS were addressed, 12 of which were given systemic corticosteroids. Six of them $(50 \%)$ stayed free, while only 1 of the 14 patients who were not given systemic corticosteroids was free. Thus the benefits of the administration of systemic steroids has statistical significance $(\mathrm{p}=0.04)$. Lower doses ( $<15 \mathrm{mg} /$ day) on alternating days led to recurrence, this implies that patients need to be maintained on systemic steroids. In our study, patients who were given systemic steroids were given oral prednisolone $(80 \mathrm{mg}$ per day) for 2 weeks, then tapered over a period of 2 more weeks. 11 of those had a decrease in serum IgE while only 3 from group B (that had 
not received oral steroids) had a decrease in serum $\operatorname{IgE}(\mathrm{p}<0.01)$.

Different studies in literature suggested and recommended various durations of treatment. In a retrospective study of 67 patients with AFRS, marked improvement for up to 12 months occurred after the intake of systemic steroids postoperatively for at least 2 months $(\mathrm{p}<0.0001)$, best results were found in patients who administered systemic steroids for up to 12 months ${ }^{[18]}$.

Antifungal agents were found to be seriously toxic. This limits the possibility of using them. Although recent preparations are less toxic and have a narrow spectrum, using them for a long time is very expensive and has minimal benefit as shown by literature ${ }^{[19]}$.

AFRS may be accompanied by different forms of atopy such as bronchial asthma, drug hypersensitivity and skin allergies. In a recent study $15 \%$ of patients had manifestations of bronchial asthma and $20 \%$ had drug hypersensitivity especially to aspirin. Esinophilia is present in 50-70\% of patients with AFRS. Manning et al ${ }^{[20]}$ mentioned that total serum $\operatorname{IgE}$ and fungus-specific $\operatorname{IgE}$ were high in AFS patients. In our series, total $\operatorname{IgE}$ was elevated in $95 \%$ of patients. Only 1 of our patients had associated bronchial asthma, while none reported any drug hypersensitivity.

In our study however, we had several similar results to previous studies and what has been there in the literature, as well as some disagreeing results. There is a statistically significant relation between the administration of systemic steroids for a prolonged period of time post-operative and the level of total serum $\operatorname{IgE}(\mathrm{p}<0.001)$. The percentage increase in the level of total serum IgE was found to be much less in patients receiving systemic steroids, in fact, in several patients the level of serum $\operatorname{IgE}$ fell between 3 and 6 months, which means that systemic steroids post-operatively lowers the levels of serum IgE.

\section{CONCLUSION}

We thus conclude, from our results and previous results in the literature, that AFRS should be treated by post-operative local and more important systemic steroids for a prolonged period of time. This might be followed by long term maintenance on local steroids alone. Patients should be followed up at close intervals (4 weeks) post-operative using serum IgE (Total and if available fungus specific) as it is a good indicator of the allergic reaction to the fungal load.

We also recommend further studies regarding immunotherapy in AFRS, prolonged study periods for more follow up of patients in the future as well as measuring fungus specific serum $\operatorname{IgE}$ to avoid fallacies that might occur from total IgE that might be elevated in some patients due to other atopic conditions.

\section{REFERENCES}

1. Huchton, et al : Allergic fungal sinusitis: an otorhinolaryngologic perspective. Allergy Asthma Proc. 2013; 24(5):307-11.

2. Rupa V., Mary Jacob, Mary Somini Mathews, Mandalam S. Seshadri: A prospective, randomised, placebo-controlled trial of postoperative oral steroid in allergic fungal sinusitis Eur Arch Otorhinolaryngol 2010; 267:233-238 DOI 10.1007/s00405-009-1075-8.

3. Arsenijevic et al: Allergic fungal sinusitisnew aspects of clinical features, laboratory diagnosis and therapy. Srp Arh CelokLek. 2013;141(910):698-704.

4. Pali-Scholl I., Jensen-Jarolim, E.: Basic aspects of allergy and hypersensityreations.Allergy Frontiers: Classification and Pathome- chanisms, 2009; 2, 317.

5. Wark, P.A.B.W., Hensley, M.J., Saltos, N., et al.: J Allergy ClinImmunol, 2003; 111, 952-957.

6. Casadevall A. Pirofski L.A.: A new synthesis for antibody-mediated immunity. Nature Immunology 2012; 13, 21-28.

7. Schubert M.S.: Allergic Fungal Sinusitis. Clinical Reviews in Allergy \& Immunology. 2006; Volume 30, Issue 3, pp 205-215

8. Bent JP III, Kuhn FA. The diagnosis of allergic fungal sinusitis. Journ Otolaryngology Head \& Neck Surgery, 1994; 111: 580-588.

9. Luong A. and Marple B. F.: Allergic Fungal Rhinosinusitis Current Allergy and Asthma Reports 2004; 4:465-470Current Science Inc. ISSN 1529-7322.

10.Schubert MS.: Allergic fungal sinusitis: pathophysiology, diagnosis and management. 
Med Mycol. 2009; 47Suppl 1:S324-30. doi: 10.1080/13693780802314809. Epub 2009 Mar 27.

11.Mutasim D. F.: What is hypersensitivity reaction? (c) Springer International Publishing Switzerland, Practical Skin Pathology, 2015; DOI 10.1007/978-3-319 14729-1_3

12.Schubert M.S.: Medical treatment of Allergic Fungal Sinusitis. Ann Allergy Asthma Immunol 2000; 85, 90-101.

13.Baldo B.A. and Pham N.H.: Drug Allergy: Clinical Aspects, Diagnosis, Mechanisms, Structure-Activity Relationships, 2013; DOI 10.1007/978-1-4614-7261-2_3, (C) Springer Science+Business Media, LLC

14.Waxman JE, Spector JG, Sale SR, Katzenstein AA: Allergic Aspergillus sinusitis: concepts in diagnosis and treatment of a new clinical entity. Laryngoscope 1987; 261-266.

15.Ragab A., Samaka R.M and Salem M.: Impact of fungal load on diagnosis and outcome of allergic fungal rhinosinusitis. Eur Arch Otorhinolaryngol 2014; 271:93-101 DOI $10.1007 / \mathrm{s} 00405-013-2467-3$
16.Ryan MW. and Marple BF.: Allergic Fungal Sinusitis T.M. Onerci and B.J. Ferguson (eds.), Nasal Polyposis, 2010; 127DOI: 10.1007/978-3642-11412-0_15, (C) Springer-Verlag Berlin Heidelberg

17.Kupferberg SB, Bent JP III, Kuhn FA.: Prognosis for allergic fungal sinusitis. Journ Otolaryngology Head \& Neck Surgery, 1997; 117: 35-41.

18.Sohail MA, Al Khabori MJ, Hyder J et al: Allergic fungal sinusitis: can we predict the recurrence? Otolaryngol Head Neck Surg 2004; 131:704-710

19.Erwin GE, Fitzgerald JE: Case report: allergic bronchopulmonary aspergillosis and allergic fungal sinusitis successfully treated with voriconazole. J Asthma 2007; 44:891-895

20.Manning SC, Mabry PI, Schafer SD, Close LG.: Evidence of IgE mediated hypertensitivity in allergic fungal sinusitis. Laryngoscope 1993; 103: 717-721. 